\title{
Design and Fabrication of Multi-Layers Infrared
} Antireflection Nanostructure on ZnS Substrate

\author{
M. Gholampour ${ }^{a, b, *}$, A. Miri ${ }^{c}$, S.I. Karanian ${ }^{a}$ And A. Mohammadi ${ }^{d}$ \\ ${ }^{a}$ Physics Group, Faculty of Basic Sciences, Imam Ali University, Tehran, Iran \\ ${ }^{b}$ Nanomaterials Group, Department of Materials Engineering, Tarbiat Modares University, \\ P.O. Box 14115-143, Tehran, Iran \\ ${ }^{c}$ Thin Film Lab., Faculty of Physics, Semnan University, Semnan, Iran \\ ${ }^{d}$ Department of management, faculty of management science, Imam Ali University, Tehran, Iran \\ (Received June 16, 2019; revised version August 18, 2019; in final form August 23, 2019)
}

\begin{abstract}
$\mathrm{MgF}_{2} / \mathrm{ZnS}$ thin films were deposited on $\mathrm{ZnS}$ substrates by physical vapor deposition (PVD) to investigate multi-layer antireflection (AR) coatings. The three-layers of $\mathrm{MgF}_{2} / \mathrm{ZnS} / \mathrm{MgF}_{2}$ with optimized thicknesses were fabricated by PVD technique and studied by Fourier-transform infrared spectroscopy (FTIR), X-ray diffraction (XRD), and field emission scanning electron microscope (FESEM). From FTIR spectroscopy it was found that in the wavelength range of $8-12 \mu \mathrm{m}$, the average transmittance of the double-side coated sample increases by about $26 \%$ and its maximum reaches about $98 \%$. The FESEM figures indicate that all the samples were uniform, compact with good adhesion on $\mathrm{ZnS}$ substrate. The XRD pattern of the $\mathrm{ZnS} / \mathrm{MgF}_{2}$ multilayer which exhibits the presence of both pristine phases of $\mathrm{MgF}_{2}$ and $\mathrm{ZnS}$, respectively.
\end{abstract}

DOI: 10.12693/APhysPolA.136.527

PACS/topics: antireflection coatings; physical vapor deposition; ZnS substrate; FTIR spectroscopy; XRD

\section{Introduction}

Zinc sulfide $(\mathrm{ZnS})$ is an important wide band gap semiconductor which is widely used in infrared optics (windows, domes etc.) in the wavelength range of 8-12 $\mu \mathrm{m}$. It has a refractive index of 2.2 at $10 \mu \mathrm{m}$ and a reflection loss of $24.7 \%$ (two surfaces) [1]. $\mathrm{MgF}_{2}$ and $\mathrm{SiO}_{2}$ are used as low refractive index material in the AR coating. Also, $\mathrm{MgF}_{2}$ has been universally used due to low refractive index and high transmittance in ultraviolet region [2]. Therefore, $\mathrm{ZnS}$ with a high refractive index and $\mathrm{MgF}_{2}$ with a low refractive index are commonly used for single- or double-layer AR coatings. Generally, refractive indices of $\mathrm{ZnS}$ and $\mathrm{MgF}_{2}$ are known to be 2.354 and 1.377 at $630 \mathrm{~nm}$, respectively [3, 4]. At present, many potential applications of $\mathrm{ZnS}$ and $\mathrm{MgF}_{2}$ such as LEDs [5], solar cells [6], photo-detectors, photovoltaic cells, solar collectors, IR diodes $[7,8]$ are being explored. The thin films of $\mathrm{ZnS}$ and $\mathrm{MgF}_{2}$ have been prepared by many deposition techniques such as thermal evaporation [9], sputtering [10], chemical bath deposition [11], SILAR [12], thermionic vacuum arc (TVA) [13], spray pyrolysis [14] and others $[15,16]$.

Most lenses and windows that are transparent in the ultraviolet region and used in optical systems have a high refractive index and therefore reflect a large part of the incidence radiation. Transmission and reflection coefficient of the surface is obtained using the following formula

* corresponding author; e-mail: mahdi.gholampour@modares.ac. ir

$$
\rho=\frac{n_{0}-n_{1}}{n_{0}+n_{1}}, \tau=\frac{2 n_{0}}{n_{0}+n_{1}},
$$

where $\rho$ is the magnitude of the reflection, $\tau$ is the magnitude of the transmission, $n_{0}$ is the refractive index of the air and $n_{1}$ is the efractive index of the layer. To have the minimum reflection in a AR coating should equate the reflectance of two surfaces in the following equation

$$
\frac{n_{0}-n_{1}}{n_{0}+n_{1}}=\frac{n_{1}-n_{s}}{n_{1}+n_{s}} \Rightarrow n_{1}=\sqrt{n_{0} n_{s}},
$$

where $n_{s}$ is the refractive index of the substrate [1]. The relationship obtained above between the refractive index of the air, layer, and substrate is the minimum condition for reflection in an AR single-layer coating. To enhance the transmittance of infrared windows, it is essential to use the multi-layers antireflection coating. Several multi-layers coatings, consisting of low and high index materials, have been applied by researchers to enhance the transmission of $\mathrm{ZnS}$ in the range of 8-12 $\mu \mathrm{m}: \mathrm{ThF}_{4} / \mathrm{ZnS}$ [17], YF3/ZnS (only designed, not measured) [18], $\mathrm{YF}_{3} / \mathrm{ZrN}$ [19], $\mathrm{YbF}_{3} / \mathrm{ZnS}$ [20], and multilayer hard carbon [21].

In this work, multi-layer AR coating such as single layer, double- and triple layer was investigated with $\mathrm{ZnS}$ and $\mathrm{MgF}_{2}$. $\mathrm{ZnS}$ and $\mathrm{MgF}_{2}$ films were deposited by physical vaper deposition (PVD), and their optical properties were examined. Based on the optical constants of each material, single-layer, double-layer, and triple-layer AR coatings were designed and fabricated on the $\mathrm{ZnS}$ substrate. The film's thickness was found out using FESEM images with the help of the Digimizer software. The structural properties of samples were studied using X-ray diffraction and the IR transmission spectra was measured with an FTIR spectrometer. 


\section{Design}

The design was performed by the Essential Macleod program (Thin Film Center Inc.), that is a comprehensive software package for the design and analysis of optical coatings. In this software, the desired characteristic (transmission/reflection/absorption) is determined by optimizing the thickness of the high and low refractive index layers. The design of the multi-layers coating was done by using $\mathrm{MgF}_{2}$ and $\mathrm{ZnS}$ on $\mathrm{ZnS}$ substrate. The optimization was performed by the simplex method at a reference wavelength of $10 \mu \mathrm{m}$. The arrangement and optimized thickness of the layers in the designed antireflection coating are as follows $\mathrm{ZnS}$ substrate/ $\mathrm{MgF}_{2} / \mathrm{ZnS} / \mathrm{MgF}_{2} / \mathrm{Air}$

\section{Experimental}

The deposition was performed by physical vapor deposition (PVD) technique in a vacuum chamber, by using the thermal boat. The deposition was performed at a pressure of $1 \times 10^{5}$ mbar. Polycrystalline $\mathrm{ZnS}$ (multispectral grade, $3 \mathrm{~mm}$ thick) were used as substrates. Before deposition, the substrates were washed with detergent in an ultrasonic bath. $\mathrm{MgF}_{2}$ (purity: $99.99 \%$ ) and ZnS (purity: 99.99\%) were evaporated by thermal boat. During the deposition process, the substrate temperature was kept at room temperature. Layer thickness and deposition rate were measured by a piezoelectric crystal. The deposition rates were 1 and $0.5 \mathrm{~nm} / \mathrm{s}$ for $\mathrm{ZnS}$ and $\mathrm{MgF}_{2}$, respectively.

The film's thickness was found out using FESEM (MIRA3 TESCAN) side images with the help of the Digimizer software program. The structural properties of samples were studied using X-ray diffraction (ADVANCE-D8 model) equipped with $\mathrm{Cuk}=1.5406$ radiation source and the IR transmission spectra was measured with an FTIR spectrometer (Shimadzu-8400S).

\section{Results and discussion}

The structural analysis and phase purity of the $\mathrm{MgF}_{2} / \mathrm{ZnS}$ films were determined by XRD pattern using X' Pert PRO Panalytical instruments, as shown in Fig. 1. This figure shows the XRD patterns of the single layer of $\mathrm{MgF}_{2}$, two layer of $\mathrm{MgF}_{2} / \mathrm{ZnS}$, and three layers of $\mathrm{MgF}_{2} / \mathrm{ZnS} / \mathrm{MgF} 2$, respectively. Figure 1 represents the tetragonal phase of $\mathrm{MgF}_{2}$ with estimated lattice constants $a=4.611 \pm 0.006 \AA, b=4.613 \pm 0.011 \AA$, $c=3.022 \pm 0.017 \AA$, comparable to standard lattice parameters $a=4.625 \AA, b=4.625 \AA, c=3.052 \AA$ (JCPDS:721150) [22]. No impurity peaks were found in the XRD pattern. Similarly, Fig. 1 represents the cubic phase of $\mathrm{ZnS}$ layer with estimated lattice constants $a=b=c=5.331 \pm 0.019 \AA$ as compared to the standard lattice parameters $a=b=c=5.345 \AA$ (JCPDS: 800020) of $\mathrm{ZnS}$ [23, 24]. The XRD pattern of the $\mathrm{ZnS} / \mathrm{MgF}_{2}$ multilayer is shown in Fig. 1, which exhibits the presence of both pristine phases of $\mathrm{MgF}_{2}$ and $\mathrm{ZnS}$, respectively. Any additional peaks, as well as secondary phases were not observed in the combined phases of the $\mathrm{ZnS} / \mathrm{MgF}_{2}$ composite except pristine $\mathrm{ZnS}$ and $\mathrm{MgF}_{2}$ peaks, which confirms that the lattice diffusion does not occur during the fabrication of alternate layers in the composite system. Comparing these data with those of single films, no extra peaks are found. Then it can be deduced that no other crystalline compound is formed during either the growth. $\mathrm{MgF}_{2}$ peaks appear at the multilayers and in thin films. This has been interpreted as a transition from amorphous to polycrystal in this material. The size of the crystals of this sample was obtained with the Debye-Sherrer formula

$$
D=\frac{0.9 \lambda}{\beta \cos \theta}
$$

where $D$ is the crystal size, $\lambda$ is the wavelength of the X-rays, $\beta$ is the half-width of the peak, and $\theta$ is Bragg's angle. In the case of three layers the obtained $\theta$ was $0.45^{\circ}$, while crystal size for final coating was $21.81 \mathrm{~nm}$. By increasing the number of layers crystallinity increases.

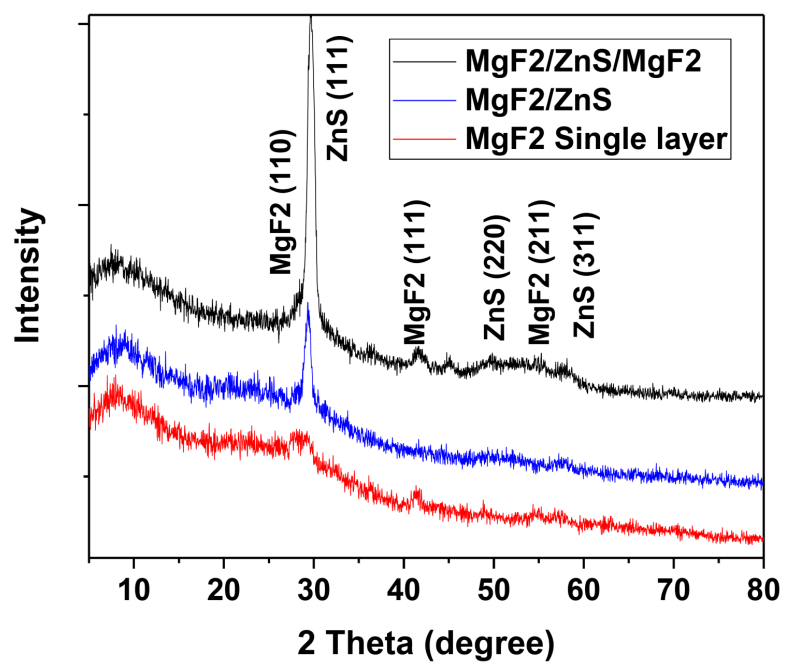

Fig. 1. The XRD patterns of the single layer of $\mathrm{MgF}_{2}$ two layer of $\mathrm{MgF}_{2} / \mathrm{ZnS}$, and three layers of $\mathrm{MgF}_{2} / \mathrm{ZnS} / \mathrm{MgF}_{2}$.

The FESEM 3D image was used to measure the thickness of the $\mathrm{MgF}_{2} / \mathrm{ZnS}$ films. Figure 2 represents the cross- section views of (a) $\mathrm{MgF}_{2}$ single layer, (b) $\mathrm{MgF}_{2} / \mathrm{ZnS}$, and (c) $\mathrm{MgF}_{2} / \mathrm{ZnS} / \mathrm{MgF}_{2}$ deposited on $\mathrm{ZnS}$ substrate. The thickness of films was obtained after processing by using digimizer software. The thickness of the $\mathrm{MgF}_{2}$ single layer was estimated to be $210 \mathrm{~nm}$. The thickness of multilayers was estimated: $(545 \pm 20 \mathrm{~nm}) \mathrm{MgF}_{2} /(482 \pm 17 \mathrm{~nm}) \mathrm{ZnS}$ and $(402 \pm 14 \mathrm{~nm}) \mathrm{MgF}_{2} /(237 \pm 8 \mathrm{~nm}) \mathrm{ZnS} /(119 \pm 6 \mathrm{~nm})$ $\mathrm{MgF}_{2}$. The figures indicate that all the samples were uniform, compact with good adhesion on $\mathrm{ZnS}$ substrate. 

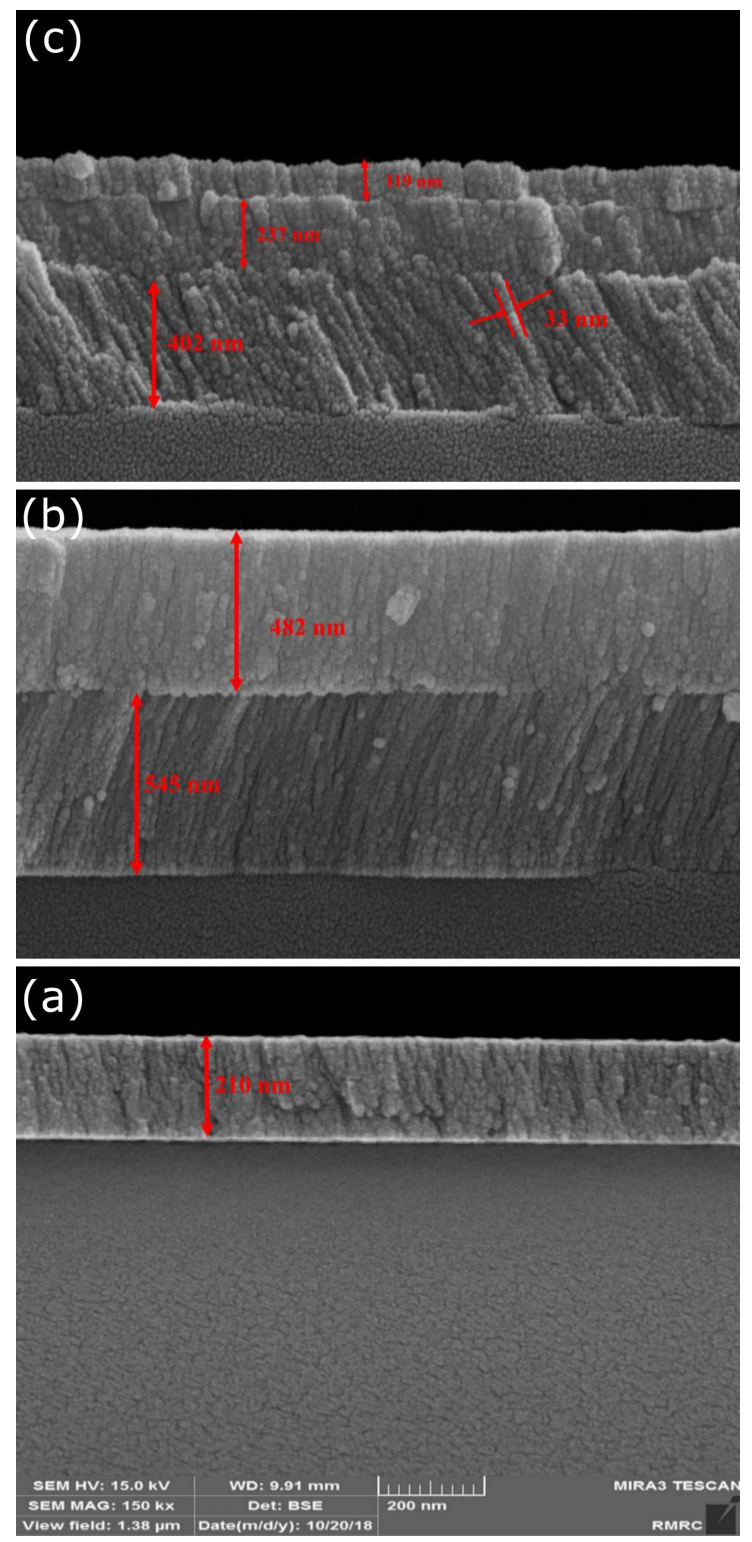

Fig. 2. The cross section views of (a) $\mathrm{MgF}_{2}$ single layer, (b) $\mathrm{MgF}_{2} / \mathrm{ZnS}$ and (c) $\mathrm{MgF}_{2} / \mathrm{ZnS} / \mathrm{MgF}_{2}$ deposited on $\mathrm{ZnS}$ substrate..

Furthermore, good agreement was found between the actual and estimated thickness of the samples. Nanostructure thickness was measured using digimizer software, as can be observed in Fig. 2c. The' average thickness of the nano-columns was about $30 \mathrm{~nm}$. Durability and environmental tests were performed on the samples by MIL-F-48616 (Salt spray: $24 \mathrm{~h}, 6.5-7.2 \mathrm{pH}$, $35^{\circ} \mathrm{C}$; Adhesion: 1 pull by scotch tape; Humidity: $24 \mathrm{~h}$, $95-100 \% \mathrm{RH}, 49^{\circ} \mathrm{C}$; Abrasion: 10 rubs by cheese cloth) and the $\mathrm{MgF}_{2} / \mathrm{ZnS} / \mathrm{MgF}_{2}$ multilayer have successfully passed durability and environmental tests.

Figure 3 shows the theatrical and experimental spectra, both in the range from 8 to $12 \mu \mathrm{m}$. We have considered two different cases: uncoated ZnS substrate and three-layer antireflection coating on one side of the substrate. It is obvious that the coating greatly enhances the IR transmission. The maximum transmittance is $78 \%$ for the uncoated ZnS substrate. With the deposition of the three-layer antireflection coating on the one side of the substrate, the maximum transmittance reaches $98 \%$. The average transmittance increases by $26 \%$ and reaches $93 \%$, in the wavelength range of $8-12 \mu \mathrm{m}$. As seen from the figure, there is a good agreement between the calculated and experimental results, especially for the one side coated case. It should be noted that to obtain the best possible agreement, we first obtained the tooling factor (thickness of film on substrate/thickness displayed on the monitor) for $\mathrm{ZnS}$ and $\mathrm{MgF}_{2}$. Then, after repeating the deposition process for several times and by using the "reverse engineering" mode of the software, the best choice for the monitor thickness was obtained. The discrepancy between the calculated and experimental spectra is more pronounced at about 8-8.5 $\mu \mathrm{m}$ for the one side coated case. Generally, the discrepancy may be attributed to tooling factor-calibrating errors, monitoring errors during layer deposition [25] and packing density of deposited coating materials [26].
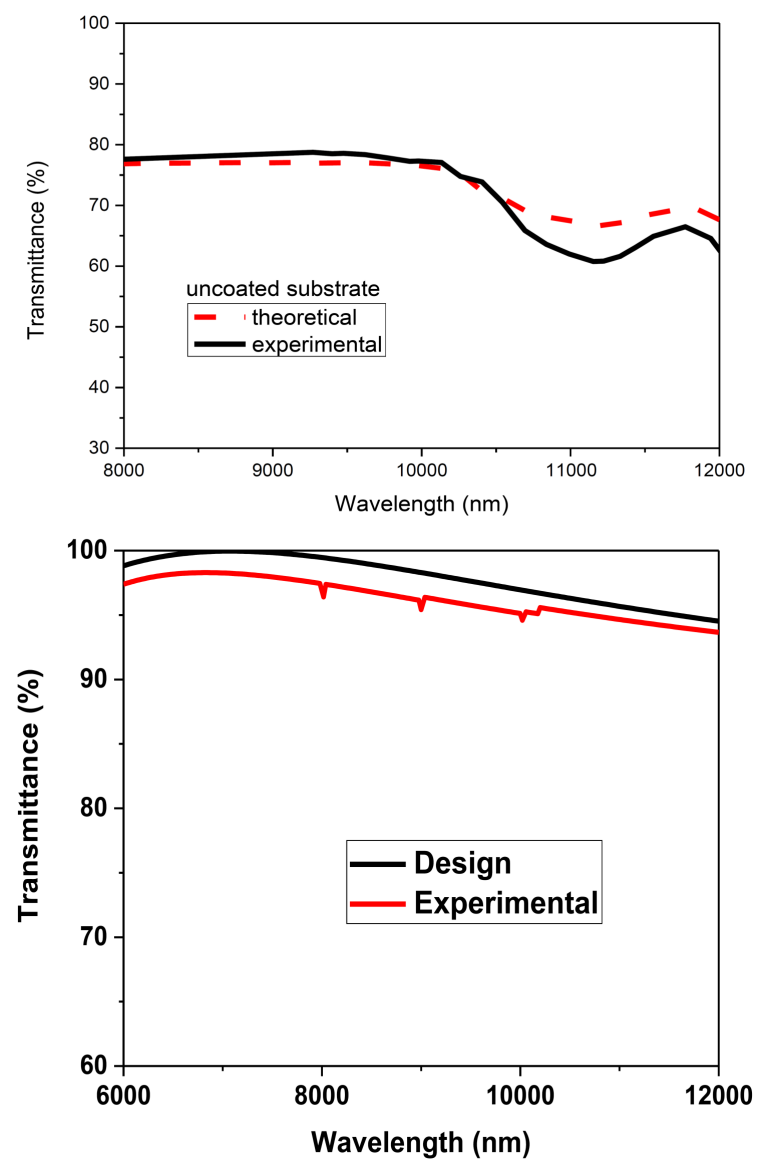

Fig. 3. The theoretical and experimental spectra, both uncoated $\mathrm{ZnS}$ substrate and three-layer anireflection coating, shown in the range from 8 to $12 \mu \mathrm{m}$. 


\section{Conclusion}

We have studied the design, fabrication, and characterization of the multi-layer antireflection coating consisting of $\mathrm{ZnS}$ and $\mathrm{MgF}_{2}$ on $\mathrm{ZnS}$ substrate. The threelayers coating $\left(\mathrm{MgF}_{2} / \mathrm{ZnS} / \mathrm{MgF}_{2}\right)$ with optimized thicknesses was fabricated by the PVD technique. From FTIR spectroscopy it was found that in the wavelength range of $8-12 \mu \mathrm{m}$, the average transmittance of the doubleside coated sample increases by about $26 \%$ and its maximum reaches about 98\%. The FESEM figures indicate that all the samples were uniform, compact with good adhesion on ZnS substrate. The XRD pattern of the $\mathrm{ZnS} / \mathrm{MgF}_{2}$ multilayer which exhibits the presence of both pristine phases of $\mathrm{MgF}_{2}$ and $\mathrm{ZnS}$, respectively.

\section{References}

[1] D.C. Harris, Materials for Infrared Windows and Domes, SPIE Optical Engineering Press, 1999.

[2] C.L. Tien, T.W. Lin, H.D. Tzeng, Y.J. Jen, M.Ch. Liu, Indian J. Pure Appl. Phys. 52, 117 (2014).

[3] E.D. Palik, Handbook of Optical Constants of Solids Academic, San Diego, 1998.

[4] E.D. Palik, Handbook of Optical Constants of Solids II Academic, San Diego, 1998.

[5] S. Nakamura, T. Sakashita, K. Yoshimura, Y. Yamada, T. Taguchi, Jpn. J. Appl. Phys. 36, 491 (1997).

[6] W. Witte, S. Spiering, D. Hariskos, Dunne Schicht 26, 23 (2014).

[7] H.A. Macleod, Thin-Film Optical Filters, Hilger, London 2001, p. 9.

[8] A. Roy Chowdhuri, D.U. Jin, C.G. Takoudis, Thin Solid Films 457, 402 (2004).

[9] P. Prathap, N. Revathi, Y.P. Venkata Subbaiah, K.T.R. Reddy, J. Phys.: Condens. Matter. 20 , 035205 (2008).
[10] D.H. Hwang, J.H. Ahn, K.N. Hui, K.S. Hui, Y.G. Son, Nanoscale Res. Lett. 7, 26 (2012).

[11] T. Liu, Y. Li, H. Ke, Y. Qian, S. Duo, Y. Hong, X. Sun, J. Mater. Sci. Tech. 32, 207 (2015).

[12] O. Ozakın, B. Guzeldir, M. Ali Yıldırım, M. Saglam, A. Ates, Phys. Stat. Solidi A. 209, 687 (2012).

[13] S. Korkmaz, S. Elmas, N. Ekem, S. Pat, M.Z. Balbă̆, Opt. Commun. 285, 2373 (2012).

[14] P.O. Offor, B.A. Okorie, F.I. Ezema, V.S. Aigbodion, C.C. DanielMkpume, A.D. Omaha, J. Alloy. Compd. 650, 381 (2015).

[15] P.P. Hankare, P.A. Chate, D.J. Sathe, A.A. Patil, Appl. Surf. Sci. 256, 81 (2009).

[16] H.M.M.N. Hennayaka, H.S. Lee, Thin Solid Films 548, 86 (2013).

[17] R. Nomura, T. Murai, T. Toyosaki, H. Matsuda, Thin Solid Films 271, 4 (1995).

[18] Y.Z. Yoo, T. Chikyow, P. Ahmet, Z.W. Jin, M. Kawasaki, H. Koinuma, J. Cryst. Growth 237, 1594 (2002)

[19] Y.P. Venkata Subbaiah, P. Prathap, K.T. Ramakrishna Reddy, Appl. Surf. Sci. 253, 2409 (2006).

[20] T. Yoshida, K. Nishimoto, K. Sekine, K. Etoh, Appl. Opt. 45, 1375 (2006).

[21] F. Huang, Q. Song, M. Li, B. Xie, H. Wang, Y. Jiang, Y. Song, Appl. Surf. Sci. 255, 2006 (2008).

[22] G. Kedawat, S. Srivastava, V.K. Jain, P. Kumar, V. Kataria, Y. Agrawal, B.K. Gupta, Y.K. Vijay, Appl. Mater. Interfaces 5, 4872 (2013).

[23] R. Maity, U.N. Maiti, M.K. Mitra, K.K. Chattopadhyay, Phys. E 33, 104 (2006).

[24] L. Qi, G.B. Mao, J.P. Ao, Appl. Surf. Sci. 254, 5711 (2008).

[25] S. Xianjun, S. Weiguo, W. Qingwang, X. Yan, H. Jiayuan, in: Proc. SPIE 6149 Design and fabrication of antireflection coatings on ZnS substrate, Xian (China) 2005, 2006, p 614907.

[26] M.B. Kala, P.K. Bandyopadhyay, B.B. Nautiyal, Infrared Phys. Technol. 55, 409 (2012). 